\title{
Analysis of US Compassionate and Geriatric Release Laws: Applying a Human Rights Framework to Global Prison Health
}

\author{
Tina Maschi ${ }^{1}$ - George Leibowitz ${ }^{2} \cdot$ Joanne Rees $^{3} \cdot$ Lauren Pappacena $^{1}$
}

Published online: 4 November 2016

(C) Springer International Publishing 2016

\begin{abstract}
The purpose of this paper was to analyze the compassionate and geriatric release laws in the USA and the role of advanced age and/or illness. In order to identify existing state and federal laws, a search of the LexisNexis legal database was conducted. Keyword search terms were used: compassionate release, medical parole, geriatric prison release, elderly (or seriously ill), and prison. A content analysis of 47 identified federal and state laws was conducted using inductive and deductive analysis strategies. Of the possible 52 federal and state corrections systems (50 states, Washington D.C, and Federal Corrections), 47 laws for incarcerated people, or their families, to petition for early release based on advanced age or health were found. Six major categories of these laws were identified: (1) physical/mental health, (2) age, (3) pathway to release decision, (4) post-release support, (5) nature of the crime (personal and criminal justice history), and (6) stage of review. Recommendations are offered, for increasing social work policy and practice expertise, and advancing the rights and needs of this population in the context of promoting human rights, aging, health, and criminal justice reform.
\end{abstract}

Keywords Older adults - Criminal justice - Compassionate and geriatric release laws $\cdot$ Content analysis $\cdot$ Human rights Social work $\cdot$ Forensic social work

Tina Maschi

tmaschi@fordham.edu

1 Graduate School of Social Service, The Justia Agenda, Fordham University, New York, NY, USA

2 School of Social Welfare, Stony Brook University, State University of New York, Stony Brook, USA

3 Department of Social Work, Long Island University, Brooklyn, USA

\section{Introduction}

Correctional systems across the globe are struggling with managing the rapidly growing aging and seriously ill population. In the USA, approximately 200,000 adults aged 55 and above are behind bars, many of which have a complex array of health, social service, and legal needs that all too often go unaddressed prior to and after their release from prison (Human Rights Watch [HRW] 2012). The large number of older people in prison is partially attributed to the passage of stricter sentencing laws, such as "Three Strikes You're Out" and the subsequent mandatory longer prison terms (American Civil Liberties Union [ACLU] 2012). These restrictive policies have created a human-made disaster in which many sentenced to long-term prison sentences will reach old age while in prison or shortly after their release. Social work, interdisciplinary scholars, and human rights advocates view the current crisis as a human rights issue that impact the rights and needs of the aging and seriously ill population (Byock 2002; HRW 2012).

\section{Compassionate and Geriatric Release Laws}

Beginning in the 1970s, there has been a growing awareness among lawmakers and other professionals, especially in the USA, of the need for compassionate and geriatric policies to address the growing aging and health crisis in prisons. Currently, medical parole and compassionate release laws, and programs for mostly nonviolent, terminally ill incarcerated people have been implemented in an effort to transition aging and/or serious or terminally ill incarcerated people to community-based care (Chiu 2010; Williams et al. 2011). Most of the social work and interdisciplinary scholarly literature in law and medicine in the USA has focused on compassionate release laws (Ferri 2013; Jefferson-Bullock 2015; Green 2014; Williams et al. 2011). The authors of these 
journal articles describe the legal/ethical practice and financial dilemmas posed when incarcerating older and seriously ill people. These authors acknowledge that, in theory, the release of persons with serious and/or terminal illness from prison to the community is cost-effective. However, there are difficulties noted in their implementation including bureaucratic red tape and negative public attitudes toward more compassionate approaches to criminal justice (Coleman 2003; Ferri 2013; Jefferson-Bullock 2015; Kinsella 2004; Green 2014; Williams et al. 2011).

To date, there has not been comprehensive human rightsbased analysis of both the compassionate and geriatric release laws in the USA. The USA is a compelling case study because it has the largest population of adults aged 50 and older $(N=$ 200,000; ACLU 2012) behind bars. Additionally, the USA has 50 states in which laws vary by provisions based on a variety of eligibility factors including age, physical and mental health, and legal status. Therefore, the purpose of this content analysis of the US compassionate and geriatric release laws was to compare the provisions of current laws and to evaluate the extent to which these were consistent with human rights guidelines. This review was guided by the following research questions: (1) What are the characteristics of compassionate and geriatric release laws in the USA? And (2) to what extent are existing compassionate and geriatric release laws consistent with core principles of a human rights framework? As detailed in the discussion section, the results of this review have implications for social work and human rights for improving social work and interdisciplinary and intersectoral responses to the treatment of criminal justice involved aging and serious and terminally ill people (Anno et al. 2004).

\section{Applying a Human Rights Framework}

Applying a human rights framework to the laws, policies, and practices with aging and seriously ill people in prison can be used to assess the extent to which these laws meet basic human rights principles. In particular, the principles of a human rights framework can provide assessment guidelines for developing or evaluating existing public health and criminal justice laws or policies, such as USA compassionate and geriatric release laws. The underlying values/principles of a human rights framework include dignity and respect for all persons, and the indivisible and interlocking holistic relationship of all human rights in civil, political, economic, social, and cultural domains (UN 1948). Additional principles include participation (especially with key stakeholder input on legal decision-making), nondiscrimination (i.e., laws and practices in which individuals are not discriminated against based on differences, such as age, race, gender, and legal history), transparency, and accountability (especially for government transparency and accountability with their citizens; Maschi 2016).
The Universal Declaration of Human Rights (UDHR) also is an instrument that provides assistance with determining the most salient human rights issues affected. Ratified in 1948 as a response to the atrocities of World War II, the UDHR was voted in favor of by 48 countries, including the USA (UN 1948). It provides the philosophical underpinnings and relevant articles to guide policy and practice responses to the aging and serious and terminally ill in prison. The UDHR preamble underscores the norm of "respect for the inherent dignity and equal and inalienable rights" of all human beings. This is of fundamental importance to crafting the treatment and release of aging and seriously ill persons in prison.

There are several UDHR articles that are important to consider when providing a rationale and response to the aging and seriously ill population in prison. For example, Article 3 states, "Everyone has the right to life, liberty, and the security of person." Article 5 states, "No one shall be subjected to torture or to cruel, inhuman or degrading treatment or punishment." Article 6 states, "Everyone has the right to recognition everywhere as a person before the law." Article 8 states "Everyone has the right to an effective remedy by the competent national tribunals for acts violating the fundamental rights granted him by the constitution or by law," and Article 25 states, "Everyone has the right to a standard of living adequate for the health and well-being of himself and of his family, including food and clothing" (UN 1948, p. 3-7).

The United Nations Office on Drugs and Crime (UNDOC 2009) Special Needs Handbook also offers additional guidelines to assess policy and practice responses to the aging and/ or seriously and terminally ill in prison. According to the UNODC (2009), older prisoners, including those with mental and physical disabilities, and terminal illnesses are a special needs population and as such are to be given special health, social, and economic practice and policy considerations (UNODC 2009). The handbook also addresses the issue of age in corrections. It is of note that the age at which individuals are defined as "older" or "elderly" in the community often differs from the definition of elderly applied in corrections. Globally, many social welfare systems, including the USA's, commonly view adults as older when they reach the age of 65 because that is when most individuals are eligible to receive full pension or social security benefits. However, although it varies among states, incarcerated persons in the USA may be classified as "older adult" or "elderly" as young as age 50 (HRW 2012; UNODC 2009).

\section{Study Significance}

The results of this review also have important implications for global social service, health and correctional systems, and policymaking bodies. While these findings may not generalize globally, conducting a comparative analysis of the regional laws of one country, such as the USA, may be useful for 
developing or refining existing laws internationally. This information also can be used by social workers to collaborate with correctional and community service providers. In particular, forensic social workers, especially those who are trained in case management, can play an important role in facilitating the release process and smooth care transitions of aging and seriously ill people released from prison (Office of the Inspector General, 2016). Local and global policy makers, including social workers, also can use these findings to craft more human rights responsive laws and policies that affect this vulnerable population.

\section{Methods}

In order to identify all of the compassionate and geriatric release laws in the USA, the research team conducted a comprehensive search of the LexisNexis legal database. The following key word search terms were used: compassionate release, medical parole, geriatric prison release, elderly (or seriously ill), and prison. Identified laws were included in the sample if they met the following criteria: (1) identified aging or seriously ill people in prison and (2) were a law or policy regarding early release from prison based on age or health status. Two trained research assistants reviewed the laws and coded the data. The team met weekly for a 6-month period with the lead researcher until $100 \%$ consensus was reached for all categories of data extracted. The search located 52 federal and state corrections systems (50 states, Washington DC, and Federal Corrections). Of the 52, 47 were found to have a law for incarcerated people or a family member (or surrogate) to petition for early release based on advanced age or health. There was no evidence of any applicable law or provision found in five states (i.e., Illinois, Massachusetts, South Carolina, South Dakota, and Utah).

\section{Data Analysis Methods}

Interpretive content analysis strategies as outlined by Drisko and Maschi (2016) were used to analyze the compassionate and geriatric release laws from the USA. Interpretive content analysis is a systematic procedure that codes and analyzes qualitative data, such as the content of published articles or legal laws. A combination of deductive and inductive approaches can be used, and this strategy was used in the current review. Deductive analysis strategies were used to extract the data by constructing preexisting categories for the criteria commonly found in compassionate and geriatric release laws (e.g., age, physical and mental health status, nature of crime). For each category, counts of state and federal laws were then calculated for frequencies and percentages of each category (e.g., 13 states had laws with age provisions).
Inductive analysis strategies were used to analyze any emerging or new categories that could not be classified in existing categories. Tutty and colleagues' (1996) four-step qualitative data analysis strategies were utilized to analyze this data. Step 1 involved identifying "meaning units" (or in-vivo codes) from the data. For example, the assignment of meaning units included the assigning codes. In step 2, second-level coding and first-level meaning units were sorted and placed in their emergent categories. Meaning unit codes were arranged by clustering similar codes into a category and separating dissimilar codes into separate categories. The data were then analyzed for relationships, themes, and patterns. In step 3 , the categories were examined for meaning and interpretation. In step 4, conceptually clustered matrices, or tables, were constructed to illustrate the patterns and themes found in the data, including characteristics of the principles of a human rights framework (Miles and Huberman 1994).

\section{Summary of Findings}

Out of 50 states plus Washington, DC, and a Federal Law (totaling 52 jurisdictions), 47 jurisdictions including Washington, DC, and the Federal Government were found to have compassionate or geriatric release laws. Five states did not have any publicly available records of compassionate or geriatric release laws (i.e., IL, MA, SC, SD, and UT). After review of the laws from these 47 legal systems in the USA (45 separate US States and D.C., as well as one federal law), basic structural consistencies were found that impacted the determination for early release or furlough from prisons based on physical or mental incapacity or advanced age. Six categories of compassionate and geriatric release laws identified were (1) physical/mental health status, (2) age, (3) nature of crime (i.e., personal and criminal justice history or risk level), (4) pathway to release decision, (5) post-release support, and (6) stage of review (i.e., initial ground-level investigation for a release petition).

\section{Physical and Mental Health Status and Life Limits}

Conditions for release in some US laws were based on physical and mental health status, including life limits. These early release or parole and furlough laws have some definition or measurement in which they can determine if an incarcerated person may be eligible for release. This included level of medical infirmity, age, and/or psychological or mental facility (see Tables 1 and 2). Some US states or federal laws used vague language about what conditions were viable for parole or furlough. In comparison, other laws were very specific about conditions for release. For example, some laws considered the potential threat to society or level of public safety risk of 
Table 1 Characteristics of laws that specify the conditions that warrant release

\begin{tabular}{|c|c|c|c|c|}
\hline & \multicolumn{2}{|c|}{ Illness is terminal or incapacitating } & \multirow[t]{2}{*}{ Mental health consideration } & \multirow[t]{2}{*}{ Age \pm disability } \\
\hline & With a lifespan time limit & Without a lifespan time limit & & \\
\hline Number of states & 17 & 19 & 17 & 14 \\
\hline Abbreviations & $\begin{array}{l}\text { AK, AR, DC, HI, KS, } \\
\text { KY, MO, MT, NC, } \\
\text { NJ, NM, NV, PA, } \\
\text { RI, TN, US FED, WY }\end{array}$ & $\begin{array}{l}\text { AL, CT, FL, GA, ID, } \\
\text { IN, KS, LA, MD, } \\
\text { MN, NE, NH, NY, } \\
\text { OH, OK, OR, TX, VT, WI }\end{array}$ & $\begin{array}{l}\text { AK, AL, AR, DE, } \\
\text { KS, MD, MI, MS, } \\
\text { NH, NJ, RI, TN, } \\
\text { TX, US FED, WI, WV, WY }\end{array}$ & $\begin{array}{l}\text { AL, CT, DC, LA, } \\
\text { MO, NC, NM, } \\
\text { OR, TX, US FED, } \\
\text { VA, WA, WI, WY }\end{array}$ \\
\hline
\end{tabular}

the incarcerated person. Other laws focused on the high cost of treatment or considered a combination of age, health, and risk factors that influenced release. There was little consistency, or even clarity, among these 47 laws about the well-being of the incarcerated people and their families, and/or victims and their families included across these US laws.

When determining if the incarcerated person's medical health warrants potential early parole or furlough, 36 laws used terminal illness as the consideration. Of those, 17 included a maximum anticipated survival period or time limit for life expectancy. For example, the US federal law includes a time limit of 18 months for the patient to survive in order to be considered for parole. In contrast, the state laws most often included a limit for life expectancy of 6 or 12 months to live. However, in one state, Kansas, the period is only 30-day life expectancy. In the 19 cases where states do not specify the time period for life expectancy, terminal illness is included as a potential factor for early release, as are terms such as "imminent peril of death" or "illness from which the inmate will not recover," or simply, "terminal illness."

The US laws also had provisions for mental or psychological health as a consideration for early release. Seventeen states included mental health capacity as a factor to consider for early parole or furlough. These 17 laws refer to any mental or psychological infirmity that results in incapacity to care for oneself or renders the person bedridden and/or incapable of caring for his or her activities of daily living (ADL). All of these laws required evaluation by both medical and mental health care professionals to make the determination of functional capacity. Only one state, Texas, mentioned "mental retardation" as a potential consideration for parole. Only the US federal prison system is quite specific in defining cognitive impairment associated with either brain injury or disease, such as Alzheimer's.

When reviewing general health conditions that may be factors for early release or furlough, many laws (27) used language that indicated that the incarcerated person was incapacitated in such a way that he/she was incapable of performing activities of daily living, or was incapacitated in general. Fifteen of the laws stated that precondition for early release was that the incarcerated person must be incapacitated either due to age, mental health, or illness, and be a low level risk to society. In some laws, assessing level of public safety risk was the only factor that the medical staff must evaluate before making an application to the parole board or judiciary. In some state laws, the healthcare costs to the prison system are a consideration for early release of an individual.

Several laws that identified criteria for early release simply used terms such as "serious medical syndrome" or "needing medical attention." Many of the states that included vague language around what constellation of factors amount to the likelihood of early release seemed to have fewer transparent processes, leaving the decision to the parole board's discretion on a case-by-case basis.

Table 2 Legal considerations for release

\begin{tabular}{|c|c|c|c|c|}
\hline & \multicolumn{4}{|c|}{ Considerations for early release for incapacitated or terminally ill patients included in legal language } \\
\hline & No threat to society & $\begin{array}{l}\text { Incapacitated so } \\
\text { cannot care } \\
\text { for self }\end{array}$ & $\begin{array}{l}\text { Cost to treat } \\
\text { is too high }\end{array}$ & $\begin{array}{l}\text { General healthcare } \\
\text { to be qualitatively } \\
\text { assessed }\end{array}$ \\
\hline Number of States & 15 & 27 & 4 & 16 \\
\hline Abbreviations & $\begin{array}{l}\text { CT, DC, LA, MD, MN, } \\
\text { MT, NM, NC, NV, OK, } \\
\text { TN, TX, US FED, VT, WY }\end{array}$ & $\begin{array}{l}\text { AK, AL, AR, CA, CT, DC, } \\
\text { GA, ID, KS, KY, MI, MN, } \\
\text { MO, NC, NE, NJ, NM, NV, } \\
\text { NY, OR, TN, TX, US FED, } \\
\text { VT, WA, WI, WY }\end{array}$ & AK, GA, RI, WA & $\begin{array}{l}\text { AL, AR, CO, DE, } \\
\text { FL, HI, IN, MI, } \\
\text { MN, MS, ND, } \\
\text { NH, NJ, OH, PA, WV }\end{array}$ \\
\hline
\end{tabular}




\section{Age as a Consideration}

Some states used age as a factor for considering early release. As illustrated in Table 3, of the 47 laws, only 13 had laws with provisions that considered age (ranging from 45 to 65 or older) as a determining factor for potential early parole (12) or furlough (1). In each law, age itself was not the sole determinant for release, but age in association with some degree of being unable to care for oneself, or an indication of some lack of capability in terms of performing activities of daily living. Most states did not define elderly. If age was defined, it mostly was delineated as 65 and older. Three states and the Federal Government limited how long an incarcerated elder must have served prior to considering advanced age as a factor for early release.

Interestingly, Oregon was the only state whose law recited language on the humane treatment of the aging population and stated that without the release of the prisoner at the advanced age/infirmity, their incarceration may be considered cruel or inhumane. All other states required that an incarcerated person of advanced age, as defined by each, had some incapacity that either was permanent and costly or rendered the incarcerated person unable to physically harm society in any way.

In several US laws, the age of the applicant was almost always considered a determining factor only in conjunction with a medical or cognitive condition. That is, age as a sole factor did not only justify release but also included the presence of a chronic and/or serious health issue. The few exceptions in state laws included Alabama and Louisiana, which considered age only as a reason to release an incarcerated person without incapacity. However, the incarcerated person's level of risk based on offense history and crimes was weighted heavily when determining release based on age without the presence of a notable serious or chronic health condition.

\section{Pathway to Release Decision}

As shown in Table 4, similar to mental and physical health considerations, the pathways to release decisions varied from state to state. Only 18 of the states had very specific and strictly defined pathways to follow for compassionate release and early parole eligibility. The more specific rules included the mechanism, such as the individual or committee that made the final determination for release or furlough. Eleven states had very clearly written rules governing physician documentation, how many or which physicians would be considered for review, and what factors must be included in their medical letter.

In these US laws, early release applications were subject to official parole board review. The series of steps in order to reach the parole board and the supporting documentation varied across laws. Of the 17 states noted above that had clearly written review procedures, most required the deputy warden,
Table 3 States including language around age as a factor for early release

States including language around age as a factor for early release

\begin{tabular}{ll}
\hline State: & Age specification: \\
Alabama & $55+$ \\
Connecticut & 65 or "advanced" \\
Louisiana & $45+$ and serving at least 20 years of a 30+ sentence \\
Missouri & "Advanced" \\
North Carolina & $65+$ \\
New Mexico & $65+$ \\
Oregon & No specification \\
Texas & No Specification \\
Virginia & $60+$ \\
Washington & No specification \\
Wisconsin & No specification \\
Wyoming & $65+$ \\
US Federal Law & $65+$ and dependent on $\%$ of time served \\
\hline
\end{tabular}

in conjunction with the prison medical director, review all documentation prior to making a submission to the parole board. Often, the laws specified that the incarcerated person or his/her family or legal advocate petitions the parole board directly. The medical director could also petition for early release if the incarcerated person could not do so themselves. The 29 states that had less clearly defined provisions often specified that parole review boards consider all information prior to rendering a final decision. At least three states had requirements that the parole board must review the request for early parole within a certain number of days (e.g., 30 days). Other laws seemed to assume that the case would be heard in a

Table 4 The pathway and process for determination of release

\begin{tabular}{|c|c|c|c|}
\hline & \multicolumn{3}{|c|}{ Process for determination of release } \\
\hline & $\begin{array}{l}\text { More malleable } \\
\text { decision-process } \\
\text { for release }\end{array}$ & $\begin{array}{l}\text { Clearly defined } \\
\text { process and rules } \\
\text { for release }\end{array}$ & $\begin{array}{l}\text { Clearly written } \\
\text { rules around } \\
\text { physician } \\
\text { documentation }\end{array}$ \\
\hline $\begin{array}{l}\text { Number of } \\
\text { States }\end{array}$ & $28 *$ & 17 & 11 \\
\hline Abbreviations & $\begin{array}{l}\text { AK, AZ, CO, CT, } \\
\text { DE, FL, GA, } \\
\text { HI, IN, KY, LA, } \\
\text { MD, MI, MN, } \\
\text { ND, NE, NH, } \\
\text { NM, OH, OK, } \\
\text { OR, PA, US } \\
\text { FED, VA, VT, } \\
\text { WA, WV, WY } \\
\text { *IA and ME have } \\
\text { precedent for } \\
\text { early parole but } \\
\text { no law in place }\end{array}$ & $\begin{array}{l}\text { AL, AR, CA, DC, } \\
\text { ID, KS, MO, } \\
\text { MS, MT, NC, } \\
\text { NJ, NV, NY, RI, } \\
\text { TN, TX, WI }\end{array}$ & $\begin{array}{c}\text { AK, AL, AZ, } \\
\text { CA, MO, } \\
\text { NC, NJ, } \\
\text { NY, TX, } \\
\text { WI, WY }\end{array}$ \\
\hline
\end{tabular}


timely manner or be reviewed by the next meeting of the parole board.

Some laws specified that a request for early release would be in the form of an application or petition to the parole board. Additionally, a submission of a post-release plan was also customary. Some laws addressed where the incarcerated person would receive post-release medical care or hospice services (Table 5). In some laws, these placements were to be vetted by the medical staff of the prison. Social workers or case managers were designated to provide other services, such as family supports, discharge planning, and care coordination.

Eighteen of the laws noted that the medical hospital or hospice, or family home with healthcare professionals, must be vetted prior to release to ensure both safety and proper healthcare. In addition, 11 of the laws mentioned that the incarcerated person must have financial resources to cover healthcare, such as Medicaid, in place prior to early release. Five of the laws mentioned a holistic style of care, including emotional support for the incarcerated person and family, as well as reintegration support. Of the states that allowed for the patient to live in the home with medical care, nine states cited "family conditions" or "support for the family as caregivers" as factors. Some laws mentioned that victim notification and participation as a condition must be met as part of the release petition.

Interestingly, many states, including the federal system, also required that the released person be closely monitored by a parole or medical officer to ensure that the released person's physical health did not improve. If the incarcerated person's condition should improve to the point they could function to perform activities of daily living or are no longer terminally ill, the incarcerated person must be returned to prison to complete their full sentence.

\section{Assessing Level of Risk: Nature of Crime (Criminal Offense History)}

As shown in Table 6, most US states/Federal prisons excluded some incarcerated people-regardless of their overall health - from potential early release. Most laws stipulated that eligibility for early parole or furlough, the incarcerated person must be convicted of an offense with potential for parole $(n=$ 25). Some jurisdictions also specified that the incarcerated person may not have been convicted of murder, either first or second degree $(n=7)$. However, most exclusions were focused upon the incarcerated person who has committed a Class A (e.g., murder or treason), B (e.g., homicide, drug trafficking, or violent assault), or C felony (e.g., some types of assault, fraud, theft, robbery, larceny, drug distribution).

In addition, 11 of the states/Federal laws and regulations excluded incarcerated persons convicted of offenses of a sexual nature. For those incarcerated persons with serious offense histories, a psychologist or psychiatrist must also investigate
Table 5 Post-release support in place for release

\begin{tabular}{|c|c|c|c|c|}
\hline & \multicolumn{4}{|c|}{ Post-release support in place } \\
\hline & $\begin{array}{l}\text { Medical facilities } \\
\text { vetted }\end{array}$ & $\begin{array}{l}\text { Financial } \\
\text { coverage }\end{array}$ & $\begin{array}{l}\text { Holistic } \\
\text { support } \\
\text { system }\end{array}$ & $\begin{array}{l}\text { Family or } \\
\text { support } \\
\text { conditions }\end{array}$ \\
\hline $\begin{array}{c}\text { Number of } \\
\text { States }\end{array}$ & 18 & 11 & 5 & 9 \\
\hline Abbreviations & $\begin{array}{c}\text { AK, DC, ID, IN, } \\
\text { KS, MD, MN, } \\
\text { MO, NC, NE, } \\
\text { NJ, NM, NY, } \\
\text { TN, TX, US } \\
\text { FED, VT, WY }\end{array}$ & $\begin{array}{l}\text { AK, AL, CO, } \\
\text { ID, KS, } \\
\text { MO, MT, } \\
\text { NY, TN, } \\
\text { US FED, } \\
\text { WY }\end{array}$ & $\begin{array}{c}\mathrm{ID}, \mathrm{MN}, \\
\mathrm{NC} \\
\mathrm{NJ} \\
\mathrm{NY}\end{array}$ & $\begin{array}{l}\text { ID, LA, } \\
\text { MD, } \\
\text { MN, } \\
\text { MT, } \\
\text { NC, NJ, } \\
\text { NY, US } \\
\text { FED }\end{array}$ \\
\hline
\end{tabular}

and determine their level of risk for potential harm to society and recidivism. Nine state laws (KS, KY, MD, MT, NC, NV, $\mathrm{NY}, \mathrm{TN}$, and WI) included provisions that victims or their families must be notified of an upcoming case for parole or furlough, and may participate in the hearing (if there is one) or submit a letter or an opinion concerning the potential release of the prisoner.

\section{Style of Review}

Forty-seven US laws differed in their style of review which ranged from strictly regulated to very discretionary release determinants. In addition to factors, such as age, physical and mental health status, and level of risk, other determinants included a state's ability to grant medical release. For example, if the governor or Deputy Warden "deemed it beneficial," either for reasons of cost or overcrowding, early release could be granted.

Table 6 Type of crime considered for early release

Type of crime considered for early release

\begin{tabular}{llll}
\hline $\begin{array}{l}\text { Ability for parole } \\
\text { and/or without }\end{array}$ & $\begin{array}{l}\text { Excluding } \\
\text { murder }\end{array}$ & $\begin{array}{l}\text { Consider } \\
\% \text { of time }\end{array}$ & $\begin{array}{l}\text { Excluding } \\
\text { sexually } \\
\text { sentence of death }\end{array}$ \\
& & served & $\begin{array}{l}\text { oriented } \\
\text { crimes }\end{array}$ \\
\hline
\end{tabular}

\begin{tabular}{lllll}
\hline $\begin{array}{l}\text { Number of } \\
\text { States } \\
\text { Abbreviations }\end{array}$ & 25 & \multicolumn{2}{c}{8} & 11 \\
& AK, CA, CT, DC, & AL, DC, & CT, DE, & AK, AL, \\
& FL, ID, KY, & LA, NJ, & IN, & AR, CO, \\
& LA, MD, MO, & NM, & MO, & ID, KY, \\
& MS, MT, NC, & NY, OR & MS, & MS, NC, \\
& NE, NH, NJ, & & NC, & NJ, TX, \\
& OR, RI, TN, & & NY, & WI \\
& TX, US FED, & OH & \\
& VA, WA, WI, & & \\
& WY & & \\
\hline
\end{tabular}




\section{Discussion}

\section{Implications for a Human Rights Approach to Social Work}

The purpose of this content analysis was to describe and analyze the compassionate and geriatric release laws in the USA. As noted in the findings section, we found that these laws had one or more provisions that fell within one of these six major categories. These categories were (1) physical/ mental health status, (2) age, (3) nature of the crime (e.g., offense history), (4) pathway to release decision, (5) postrelease support, and (6) stage of review. These finding have important implications for social workers and other key stakeholders who want to advance the human rights of justice involved vulnerable populations of older persons and persons with physical or mental disabilities or terminal illnesses, especially those in prison. The 2015 release of the Council on Social Work Education's Educational Policy (CSWE 2015) states the "purpose of the social work profession is to promote human and community well-being" (CSWE 2015, p. 1). This purpose is inclusive of all individuals regardless of their backgrounds, including criminal justice histories. Two particularly relevant skills for social workers, who want to respond to the crisis of the aging and dying in prison, are to engage in human rights and social and economic justice and to understand laws and regulations that may impact practice at the micro, mezzo, and macro levels (CSWE 2015).

The US laws governing compassionate and geriatric release are an example of an intersectional human rights issue that bridges aging, health, and criminal justice practice and policy arenas. An often unrecognized human rights area of the social work profession is the specialization of forensic social work ((Maschi and Leibowitz 2017)). Forensic social workers, who are often referred to as practicing at intersection of social work and the law, are trained in micro (e.g., clinical) and/or macro (e.g., intersectoral collaboration and policy level) interventions. In particular, geriatric forensic social workers are well positioned to prevent or intervene with the aging and dying in prison issue because of combined generalist and specialized practice knowledge and skills. Given this current crisis, a two-pronged approach to clinical and policy practice in diverse settings, such as prisons, and with diverse populations, such as incarcerated older people is necessary (Maschi et al. 2013). For example, in many of the research, practice, and policy recommendations noted in the Office of the Inspector General's report (2015), social workers can play a role in addressing all of them. These recommendations are:

1. Consider the feasibility of placing additional social workers in more institutions, particularly those with larger populations of aging inmates.
2. Provide all staff training to identify signs of aging and assist in communicating with aging inmates.

3. Reexamine the accessibility and the physical infrastructure of all of its institutions to accommodate the large number of aging inmates with mobility needs.

4. Study the feasibility of creating units, institutions, or other structures specifically for aging inmates in those institutions with high concentrations of aging inmates.

5. Systematically identify programming needs of aging inmates and develop programs and activities to meet those needs.

6. Develop sections in release preparation courses that address the post-incarceration medical care and retirement needs of aging inmates.

7. Consider revising its compassionate release policy to facilitate the release of appropriate aging inmates, including by lowering the age requirement and eliminating the minimum 10 years served requirement (Office of Inspector General, United States Department of Justice. 2015, p. 3-4).

\section{Applying a Human Rights Approach to Justice Policy Reform}

Most relevant to this paper, a human rights approach can be applied to assess the laws, policies, and practices to the extent to provisions of existing compassionate and geriatric release laws meet basic human rights principles. As described in the introduction, the principles of the human rights framework are dignity and worth of the person, the five domains of human rights (i.e., political, civil, social, economic, and cultural), participation, nondiscrimination, and transparency and accountability (UN 1948). Developed by the first author, the Compassionate and Geriatric Release Checklist (CGR-C, Maschi 2016) was created for social workers, policymakers, advocates, and other key stakeholders to use as an assessment tool to develop or amend existing compassionate or geriatric release laws (please contact the authors for a copy of the checklist). This tool also can be used by social workers to prepare expert testimony for local, state, or federal hearings or as an educational or professional training exercise. Applying a human rights framework, the checklist consists of six assessment categories for compassionate and geriatric release laws: dignity and respect of the person, promotes political, civil, economic, social, and cultural rights, nondiscrimination, participation, transparency, accountability, and special populations served.

A human rights-based analysis using the framework as highlighted in the checklist suggests that most of the provisions of each US compassionate and geriatric release often fall short of meeting the basic human rights principles that speak 
to the dignity and worth of the incarcerated person, family and victim rights and supports, and accountability and transparency on the part of the judicial and correctional systems to grant release. Additionally, the majority of the US compassionate and geriatric release laws fell short of inconclusive nondiscrimination provisions. This is especially true when assessing level of risk of incarcerated people with histories of sex or violent offenses. Based on available research, this type of provision is overly restrictive. For example, research shows that older adults with diverse offense histories have low recidivism rates (1-5\%) compared to their younger counterparts and person (ACLU 2012; Jhi and Joo 2009). For example, in a study investigating whether risk factors for recidivism remained stable across age groups $(N=1303)$, the findings showed that rates decreased in older age groups (ages 55 and older (Fazel et al. 2006). These findings are consistent with recidivism rates in studies with international samples of older sexual offenders, including research conducted in the UK, the USA, and Canada. Given these findings about older age and the reduced risk for recidivism, it is important to underscore that incarcerated individuals with violent offense histories (despite their failing health status) or elderly in US federal and state prisons are often nevertheless excluded from compassionate or geriatric release provisions (HRW 2012).

\section{Applying a Multitiered Practice Model for All Levels of Prevention and Intervention}

The 2012 Report of the United Nations High Commissioner for Human Rights (UN 2012) urges that specialized treatment be given to older adults and seriously ill people in prison and post-release. The need for specialized treatment is because many incarcerated elders experienced histories of accumulated disadvantages and currently are experiencing grave human rights conditions in prison. Therefore, when crafting a human rights-based social work, a multitiered prevention and intervention response to the current crisis and the process that led to it is needed. One helpful human rights-based practice model is Wronka's (2007) Advanced Generalist/Public Health (AGPH) Model. The AGPH model conceptualizes four interventions levels designed to prevent or alleviate social problems, such as the crisis and the process leading to the aging and seriously ill people in prison. These coincide with macro, mezzo, micro, meta-micro, and meta-macro, and research levels of intervention. Although research has its own level, it also informs all intervention levels (Wronka 2007). These levels of intervention are described and then applied to how social workers can address the aging and dying crisis below.

Macro and meta-macro levels In the AGPH model, the macro level is a target of primary intervention strategies. The macro level targets a whole national population, such as the USA, to prevent a problem, such as the crisis of aging and dying people in prison. The purpose of primary intervention strategies is to prevent individuals, families, and community from experiencing health and justice disparities (Maschi and Youdin 2012; Wronka 2007). An example of a primary intervention strategy is the development and implementation of a national campaign for criminal justice reform, especially with regard to peeling back the punitive and strict long-term sentencing policies that emerged in the 1980s. These policy advocacy strategies are an area where social worker are involved and/or could be more actively involved in crafting a more compassionate response to the aging and seriously ill in prison.

In an even larger meta-macro level, the focus is international. An example of a global prevention initiative is a social media campaign that promotes the importance of universal health and justice and fairness for all persons. Given that the criminal justice system disproportionately consists of historically underrepresented and underserved groups, such as older people, racial/ethnic minorities, and persons with physical or mental disabilities, a campaign that would promote prevention would reduce the societal oppression to prison pipeline, such as ending mass incarceration, is a potential strategy. Social workers, especially forensic social workers, can and do assume a pivotal role in these prevention efforts that advance human rights that reduce health and justice disparities for individuals of all ages and families and communities most affected by the USA's current state of hyper-incarceration (Wronka 2007).

Mezzo levels The mezzo level targets secondary intervention strategies among groups at risk, such as individuals that come to the attention of the law (Wronka 2007). These strategies may be interventions in high-risk environments, such as police stations and/or the courts. For example, a social worker can develop an alternative to incarceration/diversion program and monitor effectiveness on outcomes, such as reduced rates of imprisonment. Another example for an at-risk group is in prison settings. A social worker can develop or administer and evidence-based practice on health literacy or the management of chronic health problems that reduces the risk of rapid health decline while residing in the often unhealthy conditions of prison.

Micro and meta-micro levels The micro level is the target of tertiary intervention strategies and symptomatic populations, such as the older or serious or terminally ill population in prison. Tertiary level interventions commonly entail clinical intervention on an individual or family level, such as medical or palliative care social work interventions. For example, a social worker employed at a prison hospice may design and implement a grief therapy group for inmate peer supports or family members and monitor its effectiveness on the coping and well-being of the participants (Wronka 2007). 
The meta-micro level consisting of informal supports also is the target of tertiary intervention strategies. Although clinical interventions help with problems, everyday life social connections, such as family, friends, and others, can have therapeutic benefits. For example, a social worker in a prison can be instrumental in arranging family, volunteers, or community service provider visits to a prison or connect with families, peers, or professionals to prepare them for the release of an ill person in prison (Wronka 2007).

Research and evaluation level In the AGPH model, research and evaluation are the method of quaternary (fourth level) intervention strategies. Findings from research and evaluation studies provide informed knowledge for prevention and intervention strategies across the other intervention levels. In turn, the primary, secondary, and tertiary levels influence the research questions to be asked and the types of research methods used (Wronka 2007). For example, research is needed to provide data-driven development of policies impacting this aging and dying in population or to monitor the implementation of existing compassionate and geriatric release laws. Quantitative and qualitative methods can be used to gather data from key stakeholders.

An example of an important area of research is the reliability and validity of risk assessment (Andrews et al. 2006; Lansing 2012), especially for those with violent sex offense histories. Based on age factors, risk assessment should be attentive to the level of risk based on age (younger versus older offenders). As indicated above, recidivism rates are lower in older age groups. In a study of older sex offenders, they were found to score lower on the Static-99, a widely used actuarial measure (Hansen, 2006), and research on repeat offending (sexual and violent offenses) among an older prison population showed that recidivism decreased in the older age group (55+ years; Fazel et al. 2006). Therefore, more research is needed to accurately assess risk that accounts for age (Andrews and Dowden 2012).

\section{Limitations of the Current Review}

These findings have methodological limitations that warrant discussion. First, although a comprehensive search of the Lexis Nexus database was conducted, the extent to which all of the subject laws and possible amendments were available is unknown. Second, although multiple coders were used to select a sample of laws, classify them, and analyze their findings, it is entirely possible that other research teams may obtain different results. Third, the content analyses of categories and themes were developed deductively and inductively by the research team, and it goes without saying that a content analysis with a different set of categories and frequency counts would yield a different outcome. Yet, despite these limitations, this comprehensive analysis of the compassionate and geriatric release laws in the USA offers insight into the next steps for research and evaluation to improve conditions for the elderly and seriously and terminally ill persons in prison and for their families and communities.

\section{Conclusion}

From a human rights perspective, human beings - even individuals who have committed crimes - should receive adequate physical and psychological care in the prison system and have access to supports post-release. If incarcerated individuals are unable to receive adequate care inside prisons, it is incumbent upon social workers, advocates, and researchers to compel further investigation into the barriers to care. Potential barriers may include the potential cost of care for aging and terminally ill patients, public perception of release, expediency of the process of consideration, and level of access of timely evidence-based treatment. Supports for family members, surrogates and/or guardians, and survivors of crimes should be part of compassionate or geriatric release legislation. Social workers also should promote a compassionate care as opposed to the use of tactics that are punitive and forms of cruel and unusual punishment within the prison system and community post-release. If the standard of care available in-prison remains suboptimal to a basic standard of community care, it is social work's role to advocate for more humane prison conditions or prison release policies that result in improved care quality. It is our view that social workers grounded in human rights are the missing piece of compassion and care in our current punitive criminal justice system. Perhaps it is time to embrace our criminal justice roots for the "just" cause of promoting human rights for the aging and dying in prison.

\section{References}

American Civil Liberties Union [ACLU]. (2012). At America's expense: the mass incarceration of the elderly. Washington, DC: Author.

Andrews, D. A., \& Dowden, C. (2012). Managing correctional treatment for reduced recidivism: a metaanalytic review of program integrity. Legal and Criminological Psychology, 10, 173-187.

Andrews, D. A., Bonta, J., \& Wormith, S. J. (2006). The recent past and near future of risk and/or need assessment. Crime and Delinquency, $52,7-27$.

Anno, B., Graham, C., Lawrence, J. E., Shansky, R., Bisbee, J., \& Blackmore, J. (2004). Correctional health care: Addressing the needs of elderly, chronically ill, and terminally ill inmates. Retrieved April 1, 2010 from http://nicic.gov/library/018735. CA: Sage Publications.

Byock, I. (2002). Dying well in corrections: why should we care? Journal of Correct Health Care, 9(2), 107-117.

Chiu, T. (2010). It's about time: aging prisoners, increasing costs, and geriatric release. New York: Vera Institute of Justice. http://beepdf. 
com/doc/6114/elderly_jail_inmates_problems_prevalence_and public_health.html.

Coleman, E. A. (2003). Falling through the cracks: challenges and opportunities for improving transitional care for persons with continuous complex care needs. Journal of the American Geriatrics Society, 2003, 51(4), 549-555.

Drisko, J., \& Maschi, T. (2016). Content Analysis: Pocket Guide to Social Work Research. New York: Oxford University Press.

Fazel, S., Sjostedt, G., Langstrom, N., \& Grann, M. (2006). Risk factors for criminal recidivism in older sexual offenders. Sexual Abuse: A Journal of Research and Treatment, 18(2), 159-67.

Ferri, C. N. (2013). A stuck safety valve: the inadequacy of compassionate release for elderly inmates. Stetson Law Review, 43(1), 197-243.

Green, B. S. (2014). As the pendulum swings: the reformation of compassionate release to accommodate changing perceptions of corrections. University Of Toledo Law Review, 46(1), 123-163.

Human Rights Watch [HRW]. (2012). Old behind bars. Retrieved from http://www.hrw.org/reports/2012/01/27/old-behind-bars.

Jefferson-Bullock, J. (2015). Are you still my great and worthy opponent? compassionate release of terminally ill offenders. UMKC Law Review, 83(3), 521-564.

Jhi, K. Y., \& Joo, H. J. (2009). Predictors of recidivism among major age groups of parolees in Texas. Justice Policy Journal, 6, 1-28.

Kinsella, C. (2004). Correctional Health Care Costs. Retrieved from The Council of State Governments, Lexington, KY website: http://www. csg.org/knowledgecenter/docs/TA0401CorrHealth.pdf.

Lansing, S. (2012). New York State COMPAS-probation risk and need assessment study: Examining the recidivism scale's effectiveness and predictive accuracy. Retrieved March 1, 2013 from http://www. criminaljustice.ny.gov/crimnet/ojsa/opca/compas_probation_ report 2012.pdf.

Maschi, T. (2016). Applying a Human Rights Approach to Social Work Research and Evaluation: A Rights Research Manifesto. New York: Springer Publishing.
Maschi, T., \& Leibowitz, G. (2017). Forensic S ocial Work: Psychosocial and Legal Issues with Diverse Population and Settings (2nd ed.). New York: Springer Publishing.

Maschi, T., Viola, D., Sun, F. (2013). The high cost of the international aging prisoner crisis: well-being as the common denominator for action. The Gerontologist, 53(4), 543-554.

Maschi, T., \& Youdin, R. (2012). Social Worker as Researcher: Integrating Research with Advocacy. Boston: Pearson Publishing.

Miles, M. B., \& Huberman, A. M. (1994). Qualitative data analysis. Thousand Oaks: Sage Publications.

Office of the Inspector General, United States Department of Justice (2015). The Impact of an Aging Inmate Population on the Federal Bureau of Prisons. Washington, DC: Author.

Council on Social Work Education (2015). Final 2015 Educational Policy (EP) Developed by CSWE Commission on Educational Policy (COEP) Approved by the CSWE Board of Directors March 2015. Retrieved from: http://www.cswe.org/File.aspx?id=79793.

Tutty, L. M., Rothery, M., \& Grinnell, R. M. (1996). Qualitative research for social workers. Needham Heights: Allyn and Bacon.

United Nations (1948). The universal declaration of human rights. Available from: http://www.un.org/en/documents/udhr/

United Nations (2012). Report of the United Nations High Commissioner for Human Rights. Substantive session, 23-27 July 2012 Geneva.

United Nations Office on Drugs and Crime (2009). Handbook for prisoners with special needs. Available from: http://www.unhcr. org/refworld/docid/4a0969d42.html [accessed 6 January 2013].

Williams, B. A., Sudore, R. L., Greifinger, R., \& Morrison, R. R. (2011). Balancing punishment and compassion for seriously ill prisoners. Annals of Internal Medicine, 155(2), 122-126.

Wright, K. N., \& Bronsten, L. (2007). An original analysis of prison hospice. The Prison Journal, 87(4), 391-407.

Wronka, J. (2007). Human rights and social justice. Thousand Oaks: Sage Publications. 